\title{
Reducing unnecessary and non-indicated resuscitation attempts in COVID-19 oncology patients by improving documentation of resuscitation plan on admission including early recognition of appropriate DNACPR
}

\author{
Authors: Andrea D'Souza ${ }^{A}$ and Michel Bachour ${ }^{A}$
}

\section{Introduction and aims}

The resuscitation status of oncology patients plays an essential part of patients' care, especially during the COVID-19 pandemic. Local Guy's and St Thomas' and National Institute for Health and Care Excellence guidelines advise of cardiopulmonary resuscitation (CPR) in adult inpatients with COVID-like illness, the importance of early identification of deteriorating patients and recording treatment escalation plans and do not attempt CPR (DNACPR) discussions. ${ }^{1,2}$

Since intensive treatment unit admission and performing CPR for COVID-19 patients carries a significant risk of spread via aerosol generating procedures, eg CPR and intubation, a prompt discussion of resuscitation status and ceiling of care is required to reduce the number of inappropriate resuscitation attempts and to improve the early documentation of resuscitation status. This forms an integral part in emergency care planning, especially during the COVID-19 pandemic where shortages of critical care beds and aggressive invasive treatments are not indicated in those with poor performance statuses, as it can lead to worsening patient outcomes. ${ }^{3}$ Recent General Medical Council guidelines recommend a sensitive patient-centred approach to DNACPR discussions, where decisions are documented in notes. ${ }^{4}$

This work aims to analyse inpatient entries and assess if a TEP was made within 24 hours of admission on post-take consultant ward rounds. Oncology patients' resuscitation status was determined on their comorbidities, oncological treatment regimens and prognosis from their metastatic disease burden.

\section{Methods}

Clinical oncology inpatients were chosen as it involves a broad specialty while maintaining a large sample size equivalent to medical oncology teams at Guy's Hospital.

Data were collected retrospectively for three cycles; March, August, and September 2020 for the first, second and the third cycles, respectively. Prospective data analysis was

Author: ' Guy's and St Thomas' NHS Foundation Trust, London, UK
Table 1. First cycle results from March 2020 for

COVID-19-positive clinical oncology inpatients with

DNACPR and resuscitation status documented

within $\mathbf{2 4}$ hours of admission

COVID-19- 8 Documented 4

positive

patients

DNACPR on

admission

Documented 4 Review of TEP 2

full escalation $\quad<24$ hours of

on admission COVID-positive

result

Review of TEP 2

$>24$ hours of

COVID-positive

result

DNACPR = do not attempt cardiopulmonary resuscitation; TEP = treatment escalation plan.

conducted using e-noting medical clerking and emergency consultant admission entries used during post-take consultant ward rounds. These entries were then correlated against electronic patient records for an electronic DNACPR form submission. Interventions included formal communications with the multidisciplinary team, posters on oncology and outlying wards and local presentation of data to the oncology directorate.

Data included: date of admission, COVID-19 status, resuscitation status and documentation of TEP on admission, for all three cycles within 24 hours of admission. COVID-19 status was determined using COVID-19 swab results.

\section{Results}

Results are presented in Tables 1 and 2.

\section{Conclusion}

Based on the first cycle, two of eight COVID-positive patients did not receive revision of their resuscitation plan in the early 


\begin{tabular}{l}
$\begin{array}{l}\text { Table 2. All cycle results with resuscitation plan } \\
\text { documented for clinical oncology inpatients within } \\
\text { 24 hours of admission }\end{array}$ \\
$\begin{array}{llll}\text { Month of } & \begin{array}{l}\text { Number } \\
\text { of patient } \\
\text { records } \\
\text { reviewed }\end{array} & \begin{array}{l}\text { Number of } \\
\text { COVID-19- } \\
\text { positive } \\
\text { patients }\end{array} & \begin{array}{l}\text { Resuscitation } \\
\text { plan documented } \\
\text { on admission }\end{array} \\
\text { March } \mathbf{2 0 2 0} & 62 & 8 & 34(55 \%) \\
\begin{array}{l}\text { August } 2020 \\
\text { September }\end{array} & 25 & 0 & 19(76 \%) \\
\mathbf{2 0 2 0} & 19 & 0 & 17(89 \%)\end{array}$ \\
\hline
\end{tabular}

stages, and only $55 \%$ of inpatients had documentation of their resuscitation status on admission.

Following the interventions, a significant improvement was established in the percentage of patients having their resuscitation plan documented on admission. This was increased to $76 \%$ and $89 \%$ in August and September 2020, respectively (Table 2). COVID-19 has paved the way for early identification and accurate documentation of escalation status which is vital for improving patients' quality of care.

\section{Conflicts of interest}

None declared.

\section{References}

1 Guy's and St Thomas' NHS Foundation Trust. Covid-19 treatment escalation decision support tool. Action Card 22 v1.0, GSTT, 2020.

2 National Institute for Health and Care Excellence. Admission to Critical Care: NICE guideline [NG159]. London: NICE, 2020. www. nice.org.uk/guidance/ng159 [Accessed 03 October 2020].

3 Harding $\mathrm{H}$, Broom A, Broom J. Aerosol-generating procedures and infective risk to healthcare workers from SARS-CoV-2: the limits of the evidence. J Hosp Infect 2020;105:i717-25.

4 General Medical Council. Treatment and care towards the end of life: Working with principles and decision-making models. Manchester: GMC, 2020. www.gmc-uk.org/ethical-guidance/ethical-guidancefor-doctors/treatment-and-care-towards-the-end-of-life [Accessed 2 October 2020]. 